\title{
A comparison of urban and rural patients with chronic kidney disease referred to Inkosi Albert Luthuli Central Hospital in Durban, South Africa
}

\author{
Mitesh Singh 1,2, Nombulelo P Magula', Sudesh Hariparshad², Alain GH Assounga² \\ 'Department of Internal Medicine, King Edward VIII Hospital and University of KwaZulu-Natal, Durban, South Africa; \\ ${ }^{2}$ Department of Nephrology, Inkosi Albert Luthuli Central Hospital and University of KwaZulu-Natal, Durban, South Africa.
}

\section{ABSTRACT}

Background: The profiles of patients with chronic kidney disease (CKD) in rural areas have long been thought to differ from those of their urban counterparts. However, there have been few local studies to confirm this.

Methods: A retrospective review was conducted to compare the characteristics of patients with CKD from rural and urban areas in the South African province of KwaZulu-Natal, who were referred to Inkosi Albert Luthuli Central Hospital (IALCH) from April 2012 to April 2013.

Results: A total of 529 patients were included. The mean age of those from rural areas was lower than that of urban participants (40.6 vs. 53.4 years) and all these patients were Black. The rural patients had lower estimated glomerular filtration rates (mean values of 16.3 vs. $25.4 \mathrm{~mL} / \mathrm{min} / 1.73 \mathrm{~m}^{2}, \mathrm{P}<0.00 \mathrm{I}$ ). Regarding comorbidity, rural patients had higher rates of HIV infection (47.9\% vs. 18.3\%) but lower rates of hypertension (69.6\% vs. $83.9 \%$ ) and diabetes (20.3\% vs. 54. I\%) than the urban patients.

Conclusions: Patients with CKD referred from rural areas differed significantly from their urban counterparts. Rural patients presented at a younger age, had a higher prevalence of HIV infection, and had more advanced kidney disease at referral. Poor socio-economic circumstances limiting access to health care and less screening for CKD may have contributed to delayed referrals from rural areas.

Keywords: Chronic kidney disease; KwaZulu-Natal; rural; urban.

\section{INTRODUCTION}

There is a global rise in the prevalence of chronic kidney disease (CKD), with Europe and the United States having rates of $10.2 \%$ and $11.7 \%$, respectively [I]. Sub-Saharan Africa has an estimated CKD prevalence of I3.9\% [2]. In South Africa, a recent study by Adeniyi et al. [3] reported a prevalence of $6.1 \%$ among teachers in the Western Cape province when using the Chronic Kidney Disease Epidemiology Collaboration (CKD-EPI) study equation for estimated glomerular filtration rate (eGFR) and a prevalence of $10.0 \%$ when the Modification of Diet in Renal Disease (MDRD) study equation was used. In the cohort of Matsha et al., also in the Western Cape, the CKD prevalence was $17.3 \%$ [4].
The South African province of KwaZulu-Natal (KZN) has a population which is largely rural and socio-economically impoverished. There is a high burden of human immunodeficiency virus (HIV) infection [5] and it is likely that the prevalence of CKD, especially HIV-related CKD, will be high in this disadvantaged rural population [6]. Such a high prevalence has been observed in a cross-sectional study from Cameroon [7]. The aetiology, risk factors, clinical course and access to treatment in our rural patients may differ from those from urban areas and is the focus of this study. 


\section{METHODS}

Patients who were referred to Inkosi Albert Luthuli Central Hospital (IALCH) in Durban, KZN, for assessment for renal replacement therapy (RRT) or for renal biopsies between January 2013 and January 2014 were included in this retrospective study. These patients were referred from eight of the II municipal districts in the province (Table I). The remaining districts are serviced by Grey's Hospital in Pietermaritzburg, and patients from these areas are therefore not included in the study.

Data collected included clinical and laboratory information as detailed in Table 2. The assignment of rurality was based on the home address. Details on occupations were not available. Serum creatinine was measured using an enzymatic method and protein excretion was measured on 24-hour urine collections using a pyrogallol red-molybdate method. GFR was estimated using the MDRD equation in patients older than 18 years, and the Schwartz equation in younger patients.

\section{Definitions}

Urban refers to land that has been proclaimed as residential. Roads are formally planned and maintained by the authorities and services such as water, sewage removal, electricity and refuse removal are provided [9]. Rural refers to an area that is not classified as urban and may comprise tribal areas, commercial farms and informal settlements. Areas were considered as urban or rural according to the definitions of Statistics South Africa [9].

\section{eGFR prediction equations usng serum creatinine $\left(S_{c r}\right)$ :}

$\operatorname{MDRD}$ eGFR $\left(\mathrm{mL} / \mathrm{min} / 1.73 \mathrm{~m}^{2}\right)=$

$175 \times\left(\mathrm{S}_{\text {cr }} \text { in } \mu \mathrm{mol} / \mathrm{L} / 88.4\right)^{-1.154} \times(\text { Age in years })^{-0.203} \times$ (0.742 [if female]) [9]

Schwartz eGFR $\left(\mathrm{mL} / \mathrm{min} / 1.73 \mathrm{~m}^{2}\right)=$

$0.413 \times($ Height in $\mathrm{cm}) /\left(\mathrm{S}_{\mathrm{cr}}\right.$ in $\left.\mu \mathrm{mol} / \mathrm{L} / 88.4\right)[10]$

\section{Statistical analysis}

Data were analysed using SPSS version 23. Categorical data were described as proportions and patients from rural areas were compared with those from urban areas using the chi-squared test. Continuous data were summarised as mean \pm standard deviation (SD); non-normal data were summarised in terms of the median (interquartile range). Differences between groups were evaluated using analysis of variance (ANOVA) or the Mann-Whitney $U$ test. Logistic regression was used to analyse the association of origin (urban/rural) with various demographic and clinical para- ficance using univariate analysis were further analysed using multivariate regression.

\section{Ethical considerations}

Ethical approval was obtained from the University of KwaZulu-Natal Biomedical Research Ethics Committee (reference BE 372/I5).

\section{RESULTS}

A total of 529 patients were included in the study. The majority (87\%) had been referred from urban areas (Table I) and, in particular, from the eThekwini district (Durban metropolitan area) (72.8\%).

Table I. Nephrology referrals to IALCH from January 2013 to January 2014.

\begin{tabular}{|c|c|c|c|}
\hline District and hospital & $\begin{array}{l}\text { Popu- } \\
\text { lation }\end{array}$ & $\begin{array}{l}\text { Density } \\
\text { People/ } \\
\text { km² }^{2}\end{array}$ & $\begin{array}{c}\text { Referrals } \\
\text { Number } \\
\text { (\%) }\end{array}$ \\
\hline eThekwini & 3442361 & 1500 & $383(72.8)$ \\
\hline Addington Hospital & & & 56 \\
\hline King DiniZulu Hospital & & & 17 \\
\hline King Edward VIII Hospital & & & 38 \\
\hline $\begin{array}{l}\text { Mahatma Gandhi } \\
\text { Memorial Hospital }\end{array}$ & & & 57 \\
\hline Osindisweni Hospital & & & 9 \\
\hline $\begin{array}{l}\text { Prince Mshiyeni } \\
\text { Memorial Hospital }\end{array}$ & & & 25 \\
\hline Rahim K Khan Hospital & & & 148 \\
\hline Wentworth Hospital & & & 33 \\
\hline Ugu & 722484 & 140 & $45(8.5)$ \\
\hline G] Crookes Hospital & & & 6 \\
\hline Murchison Hospital & & & 14 \\
\hline Port Shepstone Hospital & & & 25 \\
\hline iLembe & 606809 & 190 & $47(8.1)$ \\
\hline Stanger Hospital & & & 47 \\
\hline uMkhanyakude & 625846 & 49 & $27(4.5)$ \\
\hline Bethesda Hospital & & & 6 \\
\hline Manguzi Hospital & & & 12 \\
\hline Mosvold Hospital & & & 3 \\
\hline Mseleni Hospital & & & 6 \\
\hline uThungulu & 907519 & 110 & $31(5.3)$ \\
\hline Catherine Booth Hospital & & & । \\
\hline Eshowe Hospital & & & 5 \\
\hline Ngwelezana Hospital & & & 25 \\
\hline uMgungundlovu & 1017763 & 110 & $2(0.4)$ \\
\hline Grey's Hospital & & & 2 \\
\hline Zululand & 803575 & 54 & $\mathrm{I}(0.2)$ \\
\hline Nkonjeni Hospital & & & । \\
\hline Amajuba & 499839 & 72 & $\mathrm{I}(0.2)$ \\
\hline Niemeyer Hospital & & & I \\
\hline
\end{tabular}


Table 2 compares the clinical and laboratory data of the urban and rural patients. Most patients were older than 18 years with only 13 (2.5\%) aged between 13 and 18. The mean age of the urban patients was 53.4 years and that of rural patients 40.6 years $(P<0.001)$. In the urban group, half of the patients were Black (50\%), followed numerically by Indian (42.2\%), White (5.9\%), and Coloured (mixed ancestry) patients (2\%). Patients in the rural group were exclusively Black. There were no significant differences in the sex distribution between the groups.

Regarding comorbid conditions, rural patients were less likely to have hypertension (OR 0.45, 95\% Cl 0.26-0.80) or diabetes (OR 0.22, Cl 0.12-0.40), but much more likely to have HIV infection (OR 4.50, 2.4I-6.94). There was no difference in the CD4 counts between HIV-infected patients from the two groups. The differences in com- orbidities were present even after adjusting for age by multivariate regression analysis (Table 3).

Rural patients more often had dipstick proteinuria (OR 1.32, Cl 1.07-1.62) but did not demonstrate higher 24hour urinary protein excretion. A lower mean eGFR was noted in rural patients ( 16.3 versus $25.4 \mathrm{~mL} / \mathrm{min} / 1.73 \mathrm{~m}^{2}$ ), corresponding to the higher serum urea and creatinine values. Higher levels of serum phosphate were also present in patients from rural areas (OR 2.00, Cl I.29-3.I I). Kidney sizes were similar in the two groups of patients ( 10.4 and $10.3 \mathrm{~cm}$, respectively).

The rural patients had lower total cholesterol levels (4.2 vs. $5.0 \mathrm{mmol} / \mathrm{L}$ ) and also lower mean haemoglobin levels (9.7 vs. $10.4 \mathrm{~g} / \mathrm{dL}$ ). There was no difference in the use of an angiotensin-converting enzyme inhibitor (enalapril) (OR 0.85, $\mathrm{Cl} \mathrm{0.70-1.02)} \mathrm{although} \mathrm{the} \mathrm{use} \mathrm{of} \mathrm{furosemide} \mathrm{was}$ higher among rural patients (OR 2.40, Cl I.29-3.93).

Table 2. Comparison of clinical and laboratory data of urban versus rural patients.

\begin{tabular}{|c|c|c|c|}
\hline & Urban & Rural & P-value \\
\hline Total patients & 460 (87\%) & $69(13 \%)$ & \\
\hline \multicolumn{4}{|l|}{ Demographic variables } \\
\hline Age (years) & $53.4(\mid 4.5)$ & $40.6(15.2)$ & $<0.001$ \\
\hline Ethnicity & 460 & 69 & $<0.001$ \\
\hline African & $230(50)$ & $69(100)$ & \\
\hline White & $27(5.9)$ & 0 & \\
\hline Indian & $194(42.2)$ & 0 & \\
\hline Coloured (mixed ethnicity) & $9(2)$ & 0 & \\
\hline Female sex & 248/434 (53.9\%) & $36 / 69$ (52.2\%) & 0.514 \\
\hline \multicolumn{4}{|l|}{ Comorbid conditions } \\
\hline Diabetes mellitus & $249(54.1 \%)$ & 14 (20.29\%) & $<0.001$ \\
\hline Hypertension & $386(83.9 \%)$ & $48(69.56 \%)$ & 0.007 \\
\hline HIV infection & $84(18.3 \%)$ & $33(47.87)$ & $<0.001$ \\
\hline \multicolumn{4}{|l|}{ Laboratory data } \\
\hline Viral load (copies/mL) & 3080 I ( 139427$)$ & $568319(139$ |50) & 0.690 \\
\hline Total cholesterol (mmol/L) & $5.0(1.9)$ & $4.2(1.2)$ & 0.001 \\
\hline Triglycerides (mmol/L) & $2.2(1.7)$ & $1.8(1.2)$ & 0.118 \\
\hline Corrected calcium (mmol/L) & $2.23(0.54)$ & $2.15(0.36)$ & 0.303 \\
\hline Phosphate (mmol/L) & $1.48(0.48)$ & I.70 (0.69) & $<0.001$ \\
\hline Serum glucose (mmol/L) & $7.1(2.8)$ & $6.2(2.0)$ & 0.015 \\
\hline Haemoglobin (g/dL) & $10.4(2.3)$ & $9.7(2.6)$ & 0.207 \\
\hline eGFR (mL/min/l.73 m²) & $25.4(15.9)$ & $16.3(13.4)$ & $<0.001$ \\
\hline 24-hour urine protein (g) & $2.04(2.94)$ & $1.86(2.11)$ & 0.677 \\
\hline Urea (mmol/L) & | $8.3(\mid 1.2)$ & $21.2(13.7)$ & 0.057 \\
\hline Creatinine $(\mu \mathrm{mol} / \mathrm{L})$ & $392(348)$ & $560(410)$ & $<0.001$ \\
\hline LVEF (\%) & $55(9)$ & $59(9)$ & 0.104 \\
\hline
\end{tabular}




\begin{tabular}{|c|c|c|c|}
\hline & $\mathrm{OR}^{*}$ & $95 \% \mathrm{Cl}$ & P-value \\
\hline Hypertension & 1.02 & $0.53-1.98$ & 0.948 \\
\hline Diabetes mellitus & 0.36 & $0.19-0.71$ & 0.003 \\
\hline HIV infection & 2.83 & $1.64-4.94$ & $<0.001$ \\
\hline
\end{tabular}

" OR, odds ratio; $\mathrm{Cl}$, confidence interval.

Rural patients were more likely to have inadequate access to amenities such as proper sanitation (OR 0.05, $\mathrm{Cl} 0.02-0.17$ ) or electricity (OR $0.09, \mathrm{Cl}$ 0.04-0.22). Among patients residing in urban areas, $86.5 \%$ had access to all basic amenities whereas only $8.1 \%$ of rural patients benefited in this way.

\section{DISCUSSION}

$\mathrm{KZN}$ is the province with the country's second-largest population, estimated to exceed II million people [8]. In this study, the majority of patients came from urban areas, predominantly the eThekwini district. This may be the result of more vigilant screening and the high population density of urban areas. A higher prevalence of CKD as a result of lifestyle-related disorders among patients residing in urban areas must also be considered.

In the study of Madala et al., the most prevalent comorbid conditions reported were hypertension (75.2\%), diabetes (29.8\%) and HIV (28.5\%). In our study, the rural group had a much higher prevalence of HIV infection (47.9\%), a similar prevalence of hypertension (69.6\%), and a lower prevalence of diabetes (20.3\%). The two study groups were different in that the rural participants consisted of patients presenting to a secondary level clinic and in our cases they were being referred to a tertiary/quaternary level nephrology service. The difference in HIV prevalence should be interpreted cautiously. It may be partly explained by increased rates of diagnosis in an era of easier access to voluntary HIV testing and counselling in line with the national HIV programme. Improved vigilance in screening for HIV-related diseases, such as kidney disease, and a lower threshold for referring these patients may also explain the higher HIV prevalence in this study. It is pertinent to note that the prevalence of hypertension and diabetes in rural populations remains high and that efforts to improve screening for kidney-related complications in these patients also requires prioritisation.

Rural patients had a much lower eGFR upon presentation. may contribute to the late presentation of rural patients with CKD to nephrology services. The study by Madala et al. [ I I] reported a mean eGFR of $30 \mathrm{~mL} / \mathrm{min} / 1.73 \mathrm{~m}^{2}$ in patients presenting to a rural CKD clinic. These patients may have undergone earlier screening than our patients, who had more advanced disease upon referral. This impression of later referral of patients from rural areas is further supported by their higher serum phosphate levels and lower haemoglobin levels. An important factor which may contribute to the severity of renal disease in patients from rural areas may be ethnicity. Renal risk variants in apolipoprotein I (APOLI) are associated with higher rates of CKD, and CKD progression, in Black patients, regardless of diabetes status [12].

Patients in rural areas may benefit from better living conditions as well as improved infrastructure for easier access to health care. Region-specific strategies may be most appropriate in addressing the burden of renal disease rather than applying the same measures for all South African populations.

Our study has several limitations. Poor data capture at referral hospitals resulted in incomplete data for some patients. Another limitation was the small numbers of rural patients included in the study. One reason is that the mainly rural uMgungundlovu district is served by Grey's Hospital and not IALCH. Rural patients may also have less access to health care, rural infrastructure may be inadequate to support screening programmes and rural clinicians may be less likely to refer to higher levels of care.

\section{CONCLUSIONS}

This study has demonstrated a considerable difference in the demographic and clinical profiles of patients with chronic kidney disease who are referred from a rural setting as compared to their urban counterparts in $\mathrm{KZN}$. Kidney disease is more advanced in rural patients and substantially fewer patients are referred to central hospitals from rural areas. Improvements in basic services and targeted screening programmes in rural parts of the province are needed to improve the management of CKD in these vulnerable patients.

\section{Conflict of interest}

None to declare. 


\section{REFERENCES}

I. Ayodele OE, Alebiosu CO. Burden of chronic kidney disease: an international perspective. Adv Chronic Kidney Dis. 20 10; 17(3): 215-224.

2. Stanifer JW, Jing B, Tolan S, Helmke N, Mukerjee R, Naicker S et al. The epidemiology of chronic kidney disease in sub-Saharan Africa: A systematic review and meta-analysis. Lancet Glob Health. 2014; 2(3):|74-|8|.

3. Adeniyi AB, Laurence CE, Volmink JA, Davids MR. Prevalence of chronic kidney disease and association with cardiovascular risk factors among teachers in Cape Town, South Africa. Clin Kidney J. 20 16:I-7.

4. Matsha TE, Yako YY, Rensburg MA, Hassan MS, Kengne AP, Erasmus RT. Chronic kidney diseases in mixed ancestry South African populations: prevalence, determinants and concordance between kidney function estimators. BMC Nephrol. 2013; 14:75.

5. Wabiri N, Taffa N. Socio-economic inequality and HIV in South Africa. BMC Public Health. 2013; 13: 1037.

6. Garcia-Garcia G, Jha V. Chronic kidney disease in disadvantaged populations. Braz J Med Biol Res. 2015; 48(5):377-38I.

7. Kaze FF, Meto DT, Halle M, Ngogang J, Kengne AP. Prevalence and determinants of chronic kidney disease in rural and urban Cameroonians: a cross-sectional study. BMC Nephrol. 2015; 16:1 I7.

8. Community survey 2016: Provinces-at-a-glance. Statistics South Africa, http://cs20 I6.statssa.gov.za/wp-content/uploads/2016/06/ CS-20 I 6-Provinces-at-a-glance.pdf.

9. Levey AS, Coresh J, Greene T, Stevens LA, Zhang YL, Hendriksen S, et al. Using standardised serum creatinine values in the Modification of Diet in Renal Disease study equation for estimating glomerular filtration rate. Ann Intern Med. 2006; 145:247-54.

10. Schwartz G], Work DF. Measurement and estimation of GFR in children and adolescents. J Am Soc Nephrol. 2009; 4( I I): I 832-643.

I I. Madala ND, Thusi GP, Assounga AGH, Naicker S. Characteristics of South African patients presenting with kidney disease in rural KwaZulu-Natal: a cross sectional study. BMC Nephrol. 20।4; |5(I):61.

12. Parsa A, Kao L, Xie D, Astor BC, Li M, Hsu C et al. APOLI risk variants, race, and progression of chronic kidney disease. N Engl J Med. 2013; 369:2183-96. 